\title{
Livros
}

\section{Data Review on the Physical/Chemical Removal OF CRYPTOSPORIDIUM}

\author{
AMERICAN WATER WORKS ASSOCIATION RESEARCH FOUNDATION
}

A preocupação com outros bioindicadores de qualidade de água que transcendessem os coliformes termotolerantes, em especial a $E$. Coli, agudizou-se após o surto de Cryptosporidum parvum ocorrido em Milwaukee, Wisconsin (EUA), acometendo mais de 400 mil pessoas, causando 110 óbitos em abril de 1993. Naquela ocasião, os despejos da estação de tratamento de esgoto eram lançados no mesmo lago utilizado para abastecimento público e a totalidade dos óbitos referiu-se a indivíduos com algum tipo de comprometimento do sistema imunológico. Contudo, o primeiro relato de um surto de Criptosporidiose devidamente comprovado ocorreu em San Antonio, Texas (EUA), em 1984. Posteriormente, em Carrolton, Georgia (EUA), um segundo surto infectou aproximadamente 13 mil pessoas em 1987. No ano seguinte, na Inglaterra em Ayrshire, uma infiltração de dejetos de bovinos utilizados como fertilizantes contaminou o reservatório de abastecimento da cidade, acarretando aproximadamente $44 \%$ de internaçôes, indicando uma maior virulência daquela cepa.

No período entre 1988 e 1993 , exames microbiológicos em 347 mananciais superficiais empregados para abastecimento público nos EUA detectaram a presença de Giardia e Crypto em, respectivamente, 53,9 e $60,2 \%$ dos mesmos. Embora os resultados não apontem a virulência da cepa, dificuldades têm sido encontradas no intuito de superar a dicotomia, quando do emprego do cloro e seus compostos como desinfetantes, de assegurar a inativação dos protozoários e de evitar a formação de subprodutos da desinfecção. Tal constatação agrava-se pelo estudo realizado pela United States
Environmental Protection Agency (USEPA), no estado americano do Colorado, estimando em $25 \%$ o percentual dos surtos convenientemente registrados. No período de 1986 e 1992 ocorreu redução do número de surtos (110) e dos indivíduos afetados ( $47 \mathrm{mil})$. A maioria dos surtos reportados deveu-se à ineficácia no tratamento (49\%) e à contaminação no sistema de distribuição (32\%), com significativa parcela decorrente do uso de água subterrânea sem ou com ineficiente desinfecção.

Neste contexto, a AWWA publicou uma obra direcionada a sistematizar, efetuando acurada revisão crítica, os resultados disponíveis de estudos centrados nas perspectivas de remoção e inativação de Crypto. Para tal, os autores realizaram levantamento

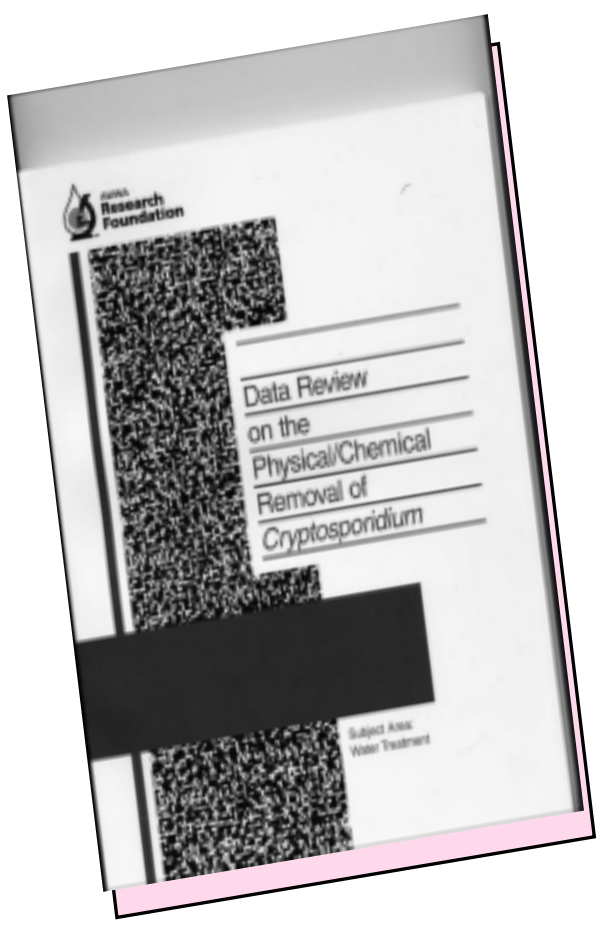

de todas as pesquisas acerca do temacom sucessivos cruzamentos das referências visando destilar as mais relevantes -, publicadas até 31 de outubro de 1998, posteriormente classificadas em três distintos níveis de importância (A, $\mathrm{B}$ e C). Esta classificação fundamentou-se no detalhamento da metodologia da pesquisa viabilizando os cálculos de remoção/inativação, na aplicabilidade específica em tratamento de água para consumo humano e na não-detecção de falhas durante a investigação experimental. Por exemplo, para um estudo enfatizando o papel da coagulaçãofloculação-sedimentação faziam-se necessárias informações versando sobre tipo e dosagem de coagulante, $\mathrm{pH}$ de coagulação, temperatura da água, e gradiente de velocidade e tempo de detenção para floculação.

A publicação realça o conceito de múltiplas barreiras como catalisador na remoção/inativação de Crypto. Desta forma, as pesquisas - e os resultados delas originários - são divididas em quatro vertentes principais, quais sejam, coagulação-floculação/flotação-sedimentação, filtração em meio granular, filtração em membrana e desinfecção. Quando os resultados das pesquisas permitiram foram delineados modelos matemáticos, sempre considerando a remoção de Crypto como variável dependente, contemplando alguns dos diversos fatores intervenientes em cada estudo. Além dos coeficientes de determinação, os modelos apresentam distintas relevâncias devido ao número de observaçōes - os próprios resultados das pesquisas - que os fundamentaram. Destaca-se, especificamente para coagulação-floculação-sedimentação - com

\section{Goordemador da columa Livgosa Prof. Gigero Onofae de Amdrade Neto}

A sessão "Livros Técnicos", que a cada edição traz resumos comentados sobre livros de interesse na área, tem como principal objetivo permitir que o leitor, de forma rápida, se atualize e conheça o que há disponível no mercado editorial. As contribuiçōes deverão ser encaminhadas para: esa@abes-dn.org.br 
remoção estimada em 1 a $2 \log$-, o modelo proposto com os resultados das pesquisas nível A que apresentou excelente aderência aos dados experimentais $\left(r^{2}=0,95 ; 24\right.$ observaçóes). O mesmo foi composto por três variáveis explicativas: dosagem de coagulante, $\mathrm{pH}$ da água bruta e dosagem de polímero. Em segundo plano o modelo delineado para filtração rápida $\left(r^{2}=0,81 ; 24\right.$ observaçōes) apresentou por sua vez como variáveis explicativas turbidez e pH do afluente, a taxa de filtração e a profundidade do meio filtrante como fatores mais relevantes na remoção de Crypto, estimada em 3 a 4 log.

Posteriormente, objetivando inferir a probabilidade de remoção/inativação de Crypto no tratamento como um todo, foi utilizado o método de Monte Carlo para a conjunção dos dois modelos anteriores. Realizaram-se, por duas vezes, $10 \mathrm{mil}$ iteraçōes, resultando em um histograma de distribuição de probabilidade focado na remoção de Crypto, apontando nas condiçôes dos ensaios - entre outras, meio filtrante com 1,4 $\mathrm{m}$ de espessura $\mathrm{e}$ turbidez afluente aos filtros inferior a 7,3 UT - para uma remoção média da ordem de 3,7 log. Os dois conjuntos de iteraçōes evidenciaram a importância de menor variabilidade da vazão afluente às unidades filtrantes na remoção de Crypto, fragilizando sob este viés o sistema de filtração a taxa declinante empregado extensivamente no País, principalmente nas estações de maior porte.
Por fim, as conclusōes do trabalho confirmam algumas premissas consensuais no meio técnico, tais como a absoluta ineficácia da desinfecção com compostos de cloro e a perspectiva do emprego associado de desinfetantes na consecução de uma maior eficiência na inativação de Crypto. Ressalta ainda que convenientemente operadas e projetadas, estaçōes com tecnologia convencional de potabilização são aptas a alcançar remoçóes de 4 a $6 \mathrm{log}$, constituindo excelente barreira à disseminação deste protozoário.

Comentários feitos por Marcelo Libânio

Professor Adjunto do Departamento de Engenharia Hidráulica e Recursos Hídricos da UFMG

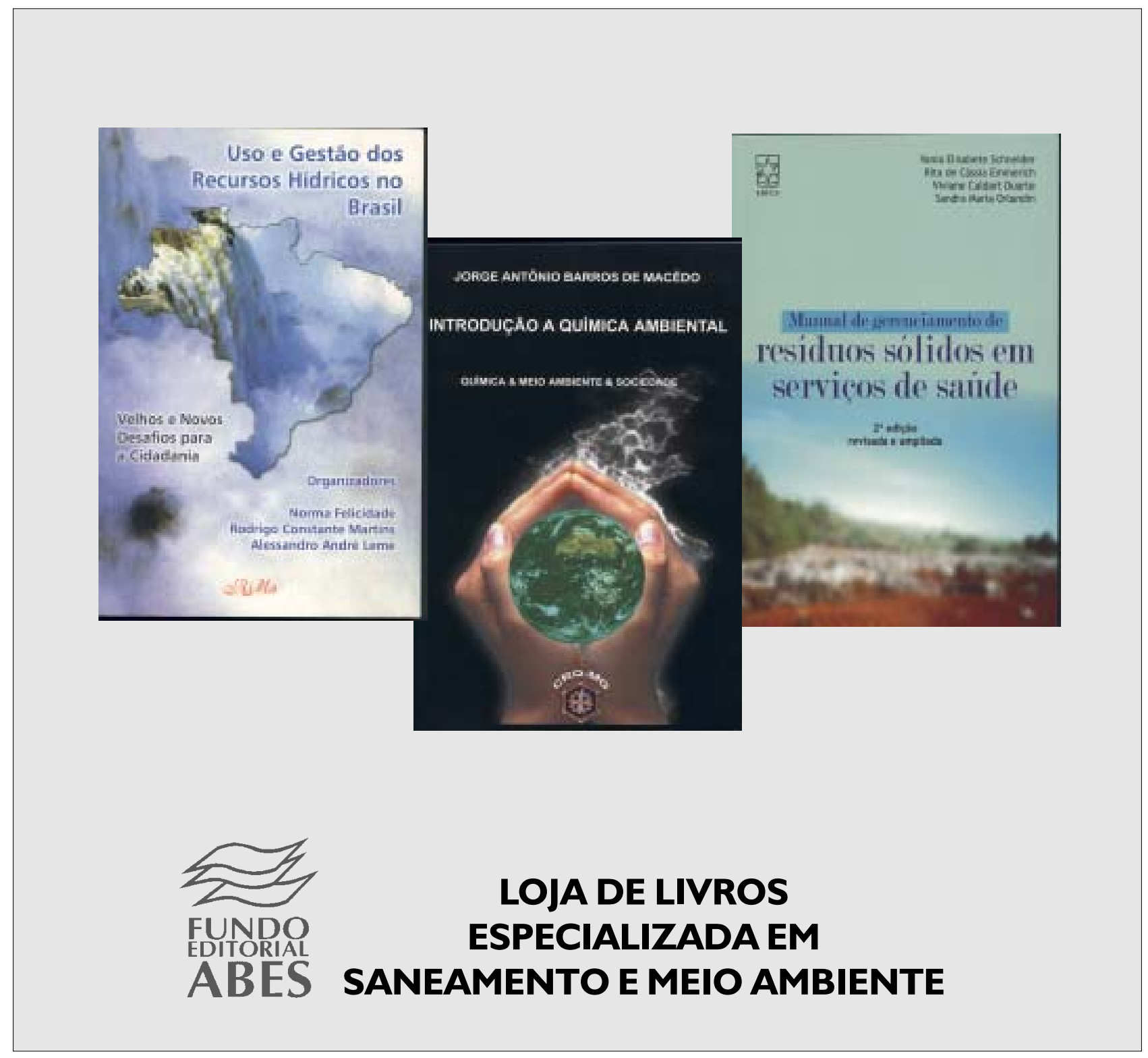

